九州大学学術情報リポジトリ

Kyushu University Institutional Repository

\title{
Application of Moso Bamboo Vinegar with Different Collection Temperature to Evaluate Fungi Resistance of Moso Bamboo Materials
}

Lin, Han Chien

Department of Forest Products Science, College of Agriculture, National Chiayi University

Murase, Yasuhide

Department of Forest and Forest Products Sciences, Faculty of Agriculture, Kyushu University

Shiah, Tsang-Chyi

Department of Forest Products Science, College of Agriculture, National Chiayi University

hwang, Gwo-Shyong

Divisions of Forest Utilization, Taiwan Forestry Research Institute(TFRI)

他

https://doi.org/10.5109/10079

出版情報：九州大学大学院農学研究院紀要. 53 (1)，pp. 107-113，2008-02-28. Faculty of Agriculture, Kyushu University

バージョン :

権利関係 : 


\title{
Application of Moso Bamboo Vinegar with Different Collection Temperatures to Evaluate Fungi Resistance of Moso Bamboo Materials
}

\author{
Han Chien LIN ${ }^{1}$, Yasuhide MURASE ${ }^{2}$, Tsang-Chyi SHIAH ${ }^{1 *}$, Gwo-Shyong HWANG ${ }^{3}$, \\ Po-Kuang CHEN ${ }^{4}$ and Wei-Lun WU ${ }^{4}$
}

\author{
Laboratory of Wood Material Technology, Division of Biomaterial Science, Department of Forest and \\ Forest Products Sciences, Faculty of Agriculture,Kyushu University, \\ Fukuoka 812-8581, Japan \\ (Received November 1, 2007 and accepted November 30, 2007)
}

\begin{abstract}
The objective of this study was to determine if the original bamboo vinegar, collected from six different temperatures (80-150, over 80, 90-92, 99-102, 120-123 and 145-150 ${ }^{\circ} \mathrm{C}$ ), obtained from Moso bamboo (Phyllostachys heterocycla), combined with a specific duration of soaking or vacuum treatment, could be used to increase the fungi resistance of bamboo. The results indicated that the absorption of bamboo vinegar was between 0.89 to $23.38 \mathrm{mg} / \mathrm{cm}^{3}$. Also, the amount of bamboo vinegar absorptions by the different bamboo specimens increased with the amount of treatment time, regardless of the type of treatment or the pre-processed bamboo material. From the results of SEM and Marco-observations, the growth rate of Aspergillus flavus, Aspergillus niger and airborne fungi particles for the collected bamboo vinegar at $120-123^{\circ} \mathrm{C}$ was about the range of $0-10 \%$ after being inoculated for over 70 days, but it was ineffective, $100 \%$ of fungal colony growth, for the control specimens after 5 days. For the bamboo vinegar collected at a temperature of $80-150{ }^{\circ} \mathrm{C}$, the airborne fungi particles and Trichoderma viride were 10-30\% and 50-90\% respectively. However, after 70 days the growth rate of Aspergillus flavus days was higher than any of the others, except for the bamboo vinegar collected at $120-123^{\circ} \mathrm{C}$. The above results show that the fungi resistance of bamboo materials is influenced by the temperature of the bamboo vinegar.
\end{abstract}

\section{INTRODUCTION}

In the $21^{\text {st }}$ century, bamboo is regarded as a green, environmentally friendly material. It is seen as a natural and renewable bioresource and has chemical and physical qualities/properties similar to wood. It quickly reaches its full potential size, which usually only takes approximately 60 to 70 days after the bamboo culms emerge from the ground (Austin and Ueda, 1970). Moreover, when considering the need for the protection of our wood resources and environmental balance, bamboo and its products show good prospects for commercial applications. It is therefore important to study the characteristics of bamboo and its by-products in order to make good use of them.

Bamboo vinegar, a by-product of the bamboo-charcoal manufacturing, includes more than 200 kinds of organic compounds, including acetic acid, phenolic compounds, alkone compounds, alcohol compounds, aldehyde compounds, and others (Uchimura et al., 2000; Ikimoto and Ikeshima, 2000; Nomura, 2004). These organic compounds in bamboo vinegar may have practical applications even when present in only trace quanti-

\footnotetext{
Department of Forest Products Science, College of Agriculture, National Chiayi University, Chiayi, Taiwan, ROC

2 Laboratory of Wood Material Technology, Division of Biomaterial Science, Department of Forest and Forest Products Sciences, Faculty of Agriculture, Kyushu University, Japan

3 Divisions of Forest Utilization, Taiwan Forestry Research Institute (TFRI), Taipei, Taiwan, ROC

${ }^{4}$ Graduate Students, Department of Forest Products Science, College of Agriculture, National Chiayi University, Chiayi, Taiwan, ROC

* Corresponding author (E-mail: tcshiah@mail.ncyu.edu.tw)
}

ties (Uchimura et al., 2000; Lin, 1995). Recently, bamboo vinegar products have been developed that are beneficial for the human skin, it is good against allergies, can be used in healthy drinks, it is virus/fungi resistant, etc (Mizuki, 2004; Hageta, 2004; Kobahasi, 2004; Yoshie, 2004). As a result, the commercial production of bamboo vinegar is being increased in Taiwan, where it being highly valued for its various effective uses such as a natural insecticide.

Previous works (Lin et al., 2006a; Shiah et al., 2006; Lin et al., 2006b) established a clear relationship between bamboo vinegar and fungi resistance for various bamboo products. The fungal resistance of bamboo increased as the total absorption of bamboo vinegar increased. At the same time, the growth rate of various fungi on the bamboo surface decreased with the increased uptake of bamboo vinegar, as measured by the exposure time to vacuum and impregnation, or steaming and soaking time. These results were proven through the use of scanning electron microscopy (SEM), C/N ratio measurements and Fourier Transform Infrared Spectroscopy (FTIR) analysis. They all suggested that bamboo vinegar was useful to restrain the molds and enabled the microbiological deterioration of bamboo materials. However, the effect of bamboo vinegar collected at different temperatures in the production process has never been studied. Therefore, the objective of this study was to evaluate if different collection temperatures of bamboo vinegar from Moso bamboo will influence the fungal resistance and so delete or decrease the need for various chemical fungicides and their impact on the environment. 


\section{MATERIALS AND METHODS}

\section{Specimen preparations \\ Bamboo}

Moso bamboo (Phyllostachys heterocycla Milf) was provided by Pu Yuan Co. Ltd., Nantou, Taiwan. The pre-processed specimens were either steamed or heated (pre-process), the same as in previous reports (Lin et al., 2006a; Shiah et al., 2006; Lin et al., 2006b). These two types of bamboo specimens were air-dried and the specimens, measuring $25 \mathrm{~mm} \times 25 \mathrm{~mm} \times 3 \mathrm{~mm}$ (Length $\times$ Weight $\times$ Thickness) were prepared. All specimens were conditioned to equilibrium at $20^{\circ} \mathrm{C}$ with $65 \%$ relative humidity $(\mathrm{RH})$ for about four weeks. Then, the average moisture content and density were measured.

Bamboo vinegar

These vinegars, collected at different temperatures during the manufacturing process of charcoal from Moso bamboo, were provided by the Division of Forest Utilization, TFRI Taipei, Taiwan. The vinegars were collected at temperatures ranging from $80^{\circ} \mathrm{C}$ to $150{ }^{\circ} \mathrm{C}$ (Uchimura et al., 2000) based on the temperature measured by a thermocouple at the exit of a smoke funnel of a furnace during the bamboo charcoal manufacturing process (pyrolysis). The different groups of bamboo vinegar were collected at 80-150, over 80, 90-92, 99-102, 120-123 and $145-150{ }^{\circ} \mathrm{C}$.

Nutrient media

Water agar (WA) was used as a nutrient media to maintain/grow the fungi to be used in the tests with either of the specimen in the petri dishes (TAPPI, 1993). WA was obtained from Merck Co. WA was prepared using $8 \mathrm{~g}$ of Agar-Agar with $400 \mathrm{ml}$ of tap water. The preparations were then mixed thoroughly prior to sterilization.

Inoculation

The 5 strains of fungi used were Aspergillus flavus, Aspergillus niger, Mucor sp., Penicillum Citrinum and Trichoderma viride. In addition, the fungi from air borne spores (airborne fungi particles) were used as one of the tested strains in this study. In other words, the bamboo specimens were exposed to the air in an indoor atmosphere for a period of $10 \mathrm{~min}$.

\section{Experimental methods}

Soaking and vacuum treatments

The Moso bamboo specimens for both the steamed and the heated specimens were soaked with the different bamboo vinegars for 2 different periods, $2880 \mathrm{~min}$ (2 days) and $5760 \mathrm{~min}$ (4 days). For the vacuum treatment, the specimens were individually treated with various bamboo vinegars, using a vacuum apparatus. The volume was kept under a constant pressure of over $600 \mathrm{~mm} / \mathrm{Hg}$, and was then impregnated with each type of bamboo vinegar. There were two different treatment conditions: one consisted of $30 \mathrm{~min}$ of vacuum and 120 min of impregnation time, and the other consisted of $60 \mathrm{~min}$ of vacuum period and $240 \mathrm{~min}$ of impregnation time.

The specimens were removed individually to a drain- age pad, and tipped on end to allow for drainage. The specimens were then briefly wiped with a paper towel to remove the surface vinegar and were then weighed to determine the amount of absorption. Afterwards, the specimens were air dried for $24 \mathrm{~h}$, and then placed into a convection oven at $30^{\circ} \mathrm{C}$ for over 30 min after which they were cooled and stored in plastic bags for at least 3 days to allow the bamboo vinegar fixation reaction to proceed. They were then reconditioned at $20{ }^{\circ} \mathrm{C}$ with $65 \% \mathrm{RH}$ for 2 weeks. Six replicates of specimen were prepared for each type of fungi and for each of the treatments, respectively.

Fungi inoculation and fungal resistance

Each fungus was inoculated by distributing 3 drops (about $3 \mathrm{~mL}$ ) onto the surface of the specimen in a petri dish, and then incubating the petri dishes containing the inoculated test-specimens at a temperature of $25^{\circ} \mathrm{C}$ in a humid atmosphere till the growth of each tested fungus was seen. The fungal resistance experiments were determined by visual examination.

Absorption

The absorption was calculated using the following equation:

Absorption $\left(\mathrm{mg} / \mathrm{cm}^{3}\right)=(\mathrm{Wa}-\mathrm{Wb}) \mathrm{C} \times 10 / \mathrm{V}$

where $\mathrm{Wa}$ is the weight of the specimen before

either of treatment, and $\mathrm{Wb}$ is the weight of the specimen after either of treatment. C is the solid content. $\mathrm{V}$ is the volume of the specimen.

Surface texture

Using a surface-texture measuring instrument (Semitsu, Tokyo), the surface texture of each specimen for each type of bamboo was measured. This measurement included the degree of texture of both vertical and horizontal fiber directions at the surface of the specimen. The average degree of the surface texture on the centerline of the specimen $(\mathrm{Ra})$, the degree of the texture at the highest point on the surface of the specimen (Rmax), and the average degree of the texture for ten points on the surface of the specimen (Rz) were measured.

Color value

The specimens for both the steaming and the carbonizing processes were measured using a colorimeter (Nippon Denshoku NR-3000) at 3 randomly selected spots. In the CIE $1976 \mathrm{~L}^{*} \mathrm{a}^{*} \mathrm{~b}^{*}$ color system employed, color is considered to consist of three major dimensions: hue, chroma, and lightness. L* is the lightness or brightness variable and is generally the most important aspect of wood color changes to a viewer's eye, while $\mathrm{a}^{*}$ and $\mathrm{b}^{*}$ represent the chromaticity (hue and chroma) coordinates. The color difference $\left(\Delta \mathrm{E}^{*}\right)$ was evaluated as well.

Statistics analysis

The results of the basic properties and absorption were statistically analyzed based on Duncan's multiple range tests at a 5\% significance level using the Statistical Package for Social Science (SPSS) software.

$C / N$ ratio measurement

The samples, each weighing about 2- $4 \mathrm{mg}$ and oven dried, with various fungi that were individually inoculat- 
ed on each of the specimens were analyzed after 70 days using an Elemental Vario CHNS/O analyzer (EA, Germany). The result of the $\mathrm{C}$ and $\mathrm{N}$ elements was obtained and then the $\mathrm{C} / \mathrm{N}$ ratio was calculated.

Microscopic observation

In order to determine the growth of the tested fungi, the cross section of each specimen measuring $0.5 \mathrm{~cm} \times 0.5 \mathrm{~cm}$ was taken, and then observed using a scanning electron microscope (SEM, HITACH S-2400 types) at $300 \times$ magnification.

\section{RESULTS AND DISCUSSION}

\section{Basic properties}

Moso bamboo vinegar was collected according to the temperature measured by a thermocouple at the exit of a smoke funnel of a furnace during the manufacture of bamboo charcoal. The collected vinegars were classed into six groups ranging from 80 to $150{ }^{\circ} \mathrm{C}$. The groups were collected at 80-150, over 80, 90-92, 99-102, 120123 and $145-150{ }^{\circ} \mathrm{C}$. Table 1 shows the basic properties of Moso bamboo vinegar for the different collection temperatures. The $\mathrm{pH}$ value of the vinegars ranged from 1.5 to 3.0 , the organic acid content ranged from 3.52 to $7.21 \%$, specific gravity was between 1.006 and 1.014 (between 29.5 and $30{ }^{\circ} \mathrm{C}$ ), and the solid content (soluble tar content) was from 0.048 to $0.503 \%$. These vinegars ranged from light yellow to yellowish-brown in color and the color difference of the vinegar increased with the increase in temperature.

The basic properties of the two types of pre-proc- essed specimens were investigated. The results are shown in Table 2. The air-dried moisture content was between 9.0 and $10.0 \%$ and the density of either airdried or oven-dried condition ranged from 0.56 to $0.95 \mathrm{~g} /$ $\mathrm{cm}^{3}$. The Ra, Rmax and Rz of the degree of texture for both the horizontal and the vertical fibers directions was 3.64 to $6.08,21.77$ to 56.16 and 14.22 to 38.09 , respectively. Color changes are generally the most important aspect of wood-based materials to a consumer, particularly for furniture or floor use, and $\mathrm{L}^{*} \mathrm{a}^{*} \mathrm{~b}^{*}$ are also the most frequently measured parameters (Okano et al., 1995). Results of the colorimetric measurements of the two types of bamboo specimens, based on the CIE L* $\mathrm{a}^{*}$ $b^{*}$ system, are also shown in Table 2 . The results of the $\mathrm{L}^{*}, \mathrm{a}^{*}$ and $\mathrm{b}^{*}$ were $83.97,2.74$ and 25.71 for the steamed specimens, and $60.79,8.45$ and 26.76 for the heated ones. The color value of the steamed specimens was lighter than that of the heated one. This is because the visual color of the steamed specimens was a light yellow material and the color of the heated specimens was a yellowish-brown material, after both them are pre-processed.

To examine the influence of the different treatments on the absorption of bamboo vinegar collected at different temperatures, two types of treatments were carried out. The absorption for both the steamed and the heated bamboo specimens are shown in Table 3. The results showed that the absorptions of bamboo vinegar were 1.29 to $19.96 \mathrm{mg} / \mathrm{cm}^{3}$ and 2.43 to $23.38 \mathrm{mg} / \mathrm{cm}^{3}$, as well as 1.54 to $18.39 \mathrm{mg} / \mathrm{cm}^{3}$ and 2.06 to $19.03 \mathrm{mg} / \mathrm{cm}^{3}$ for the steamed and heated specimens after 2 and 4 days of

Table 1. Basic properties of Moso bamboo vinegar with the different collected temperatures

\begin{tabular}{|c|c|c|c|c|c|c|}
\hline \multirow{2}{*}{$\begin{array}{c}\text { Bamboo Vinega } \\
\left({ }^{\circ} \mathrm{C}\right)\end{array}$} & \multirow{2}{*}{$\mathrm{pH}$ value } & \multirow{2}{*}{$\begin{array}{c}\text { Organic acid content } \\
\qquad \%)\end{array}$} & \multicolumn{2}{|c|}{ Specific gravity (SG) tests } & \multirow{2}{*}{$\begin{array}{l}\text { Solid content } \\
(\%)^{1)}\end{array}$} & \multirow{2}{*}{$\Delta \mathrm{E}^{* 2)}$} \\
\hline & & & Temperature $\left({ }^{\circ} \mathrm{C}\right)$ & SG & & \\
\hline $80-150$ & 3.0 & $3.52(0.06)^{\text {a } 3)}$ & 29.5 & 1.006 & $0.048(0.02)^{\mathrm{a}}$ & $4.58(0.19)^{\mathrm{a}}$ \\
\hline Over 80 & 1.5 & $6.28(0.29)^{\mathrm{d}}$ & 30.0 & 1.010 & $0.121(0.04)^{b}$ & $8.11(0.19)^{b}$ \\
\hline $90-92$ & 1.6 & $5.87(0.26)^{c}$ & 29.0 & 1.010 & $0.118(0.12)^{\mathrm{b}}$ & $6.93(0.32)^{a}$ \\
\hline $99-102$ & 2.0 & $6.35(0.08)^{d}$ & 29.5 & 1.012 & $0.169(0.01)^{c}$ & $9.42(0.33)^{b}$ \\
\hline $120-123$ & 2.1 & $7.21(0.08)^{\mathrm{e}}$ & 30.0 & 1.014 & $0.406(0.02)^{d}$ & $15.54(0.48)^{d}$ \\
\hline $145-150$ & 2.7 & $5.28(0.10)^{b}$ & 30.0 & 1.012 & $0.503(0.04)^{e}$ & $13.51(0.29)^{c}$ \\
\hline
\end{tabular}

1) Solid content: Soluble tar content

2) $\Delta \mathrm{E}^{*}=\left(\Delta \mathrm{L}^{* 2}+\Delta \mathrm{a}^{* 2}+\Delta \mathrm{b}^{* 2}\right)^{1 / 2}$ : Color difference.

3) Mean (standard deviation) separation within columns by Duncan's multiple range tests at $5 \%$ significant level.

Table 2. Basic properties of Moso bamboo specimens

\begin{tabular}{|c|c|c|c|c|c|c|c|c|c|c|c|c|}
\hline \multirow{2}{*}{$\begin{array}{l}\text { Types of } \\
\text { specimen }\end{array}$} & \multirow{2}{*}{$\begin{array}{c}\text { Air-dried } \\
\text { moisture } \\
\text { content } \\
(\%)\end{array}$} & \multirow{2}{*}{$\begin{array}{c}\text { Air-dried } \\
\text { density } \\
\left(\mathrm{g} / \mathrm{cm}^{3}\right)\end{array}$} & \multirow{2}{*}{$\begin{array}{c}\text { Oven-dried } \\
\text { density } \\
\left(\mathrm{g} / \mathrm{cm}^{3}\right)\end{array}$} & \multicolumn{3}{|c|}{$\begin{array}{l}\text { Texture degree to horizontal } \\
\text { fiber direction }(\mu \mathrm{m})\end{array}$} & \multicolumn{3}{|c|}{$\begin{array}{l}\text { Texture degree to vertical } \\
\quad \text { fiber direction }(\mu \mathrm{m})\end{array}$} & \multicolumn{3}{|c|}{ Color value } \\
\hline & & & & $\mathrm{Ra}^{2)}$ & $\operatorname{Rmax}^{2)}$ & $\mathrm{Rz}^{2)}$ & $\mathrm{Ra}$ & Rmax & $\mathrm{Rz}$ & $\mathrm{L}^{* 3)}$ & $a^{* 3)}$ & $b^{* 3)}$ \\
\hline $\begin{array}{l}\text { Steamed } \\
\text { specimen }\end{array}$ & $\begin{array}{c}10.0 \\
(0.69)^{1)}\end{array}$ & $\begin{array}{c}0.62 \\
(0.03)\end{array}$ & $\begin{array}{c}0.56 \\
(0.03)\end{array}$ & $\begin{array}{c}3.64 \\
(0.85)\end{array}$ & $\begin{array}{l}30.87 \\
(6.26)\end{array}$ & $\begin{array}{l}22.31 \\
(4.90)\end{array}$ & $\begin{array}{c}6.08 \\
(1.71)\end{array}$ & $\begin{array}{c}56.16 \\
(15.66)\end{array}$ & $\begin{array}{c}38.09 \\
(11.35)\end{array}$ & $\begin{array}{l}83.97 \\
(1.10)\end{array}$ & $\begin{array}{c}2.74 \\
(0.32)\end{array}$ & $\begin{array}{l}25.71 \\
(0.87)\end{array}$ \\
\hline $\begin{array}{l}\text { Heated } \\
\text { specimen }\end{array}$ & $\begin{array}{c}9.0 \\
(1.45)\end{array}$ & $\begin{array}{c}0.95 \\
(0.09)\end{array}$ & $\begin{array}{c}0.87 \\
(0.07)\end{array}$ & $\begin{array}{c}2.25 \\
(0.74) \\
\end{array}$ & $\begin{array}{l}21.77 \\
(6.87)\end{array}$ & $\begin{array}{l}14.22 \\
(5.50)\end{array}$ & $\begin{array}{c}5.57 \\
(0.91)\end{array}$ & $\begin{array}{c}48.03 \\
(13.53)\end{array}$ & $\begin{array}{l}32.06 \\
(6.74)\end{array}$ & $\begin{array}{l}60.79 \\
(3.27) \\
\end{array}$ & $\begin{array}{c}8.45 \\
(0.78) \\
\end{array}$ & $\begin{array}{l}26.76 \\
(0.95)\end{array}$ \\
\hline
\end{tabular}

1) Mean (standard deviation) separation within the same column.

${ }^{2)} \mathrm{Ra}$ : Average surface texture degree on centerline of specimen; Rmax: Texture degree of maximum high point on surface specimen; Rz: Texture degree for average ten points on surface specimen.

${ }^{3)}$ Color values: L*: 0 to 50 dark direction, 51 to 100 light direction; $\mathrm{a}^{*}$ : 0 to +60 red direction, 0 to -60 green direction; $\mathrm{b}^{*}$ : 0 to +60 yellow direction, 0 to- 60 blue direction. 
Table 3. Absorption of bamboo vinegar with the different collected temperatures for Moso bamboo specimens with two types of treatments.

Unit: $\mathrm{mg} / \mathrm{cm}^{3}$

\begin{tabular}{|c|c|c|c|c|c|c|c|c|}
\hline \multirow{3}{*}{$\begin{array}{c}\text { Bamboo } \\
\text { vinegar } \\
\left({ }^{\circ} \mathrm{C}\right)\end{array}$} & \multicolumn{4}{|c|}{ Steamed specimen } & \multicolumn{4}{|c|}{ Heated specimen } \\
\hline & \multicolumn{2}{|c|}{ Soaking treatment (min) } & \multicolumn{2}{|c|}{ Vacuum treatment (min) } & \multicolumn{2}{|c|}{ Soaking treatment (min) } & \multicolumn{2}{|c|}{ Vacuum treatment (min) } \\
\hline & 2 & 4 & 120 & 240 & 2 & 4 & 120 & 240 \\
\hline $80-150$ & $1.29(0.59) \mathrm{a}^{1)}$ & $2.43(0.33) \mathrm{a}$ & $0.89(0.19) \mathrm{a}$ & $1.26(0.13) \mathrm{a}$ & $1.54(0.43) \mathrm{a}$ & $2.06(0.16) \mathrm{a}$ & $0.90(0.05) \mathrm{a}$ & $1.31(0.46) \mathrm{a}$ \\
\hline Over 80 & $3.89(1.09) b$ & $5.52(1.33) \mathrm{b}$ & $2.47(1.24) \mathrm{b}$ & $3.01(0.31) b$ & $4.49(0.51) \mathrm{b}$ & $4.98(0.57) \mathrm{b}$ & $2.28(0.10) \mathrm{b}$ & $2.58(0.17) \mathrm{b}$ \\
\hline $90-92$ & $4.50(1.09) \mathrm{b}$ & $5.27(1.10) \mathrm{b}$ & $2.41(0.46) \mathrm{b}$ & $2.88(0.42) b$ & $4.00(0.34) \mathrm{b}$ & $4.20(1.16) \mathrm{b}$ & $2.33(0.16) b$ & $2.98(0.18) b$ \\
\hline $99-120$ & $6.64(2.24) c$ & $8.39(1.32) c$ & $3.64(0.64) c$ & $3.93(0.41) c$ & $6.18(0.59) \mathrm{c}$ & $6.84(0.92) c$ & $3.43(0.17) \mathrm{c}$ & $5.44(0.39) \mathrm{c}$ \\
\hline $120-123$ & $14.54(2.20) \mathrm{d}$ & $18.69(3.86) \mathrm{d}$ & $8.06(1.73) \mathrm{d}$ & $8.84(1.65) d$ & $15.21(2.67) \mathrm{d}$ & $16.67(2.16) \mathrm{d}$ & $7.36(0.36) d$ & $12.07(2.61) \mathrm{d}$ \\
\hline $145-150$ & $19.96(3.67) \mathrm{e}$ & $23.38(4.42) \mathrm{e}$ & $10.18(2.10) \mathrm{e}$ & $9.90(0.76) \mathrm{e}$ & $18.39(1.46) \mathrm{e}$ & $19.03(1.98) \mathrm{e}$ & $9.53(0.67) \mathrm{e}$ & $11.74(3.04) d$ \\
\hline
\end{tabular}

${ }^{1)}$ Mean (standard deviation) separation within columns by Duncan's multiple range tests at $5 \%$ significant level.

soaking, respectively. For the vacuum treatments with 30 min of vacuum and 120 min of impregnation time and 60 min of vacuum period and 240 min of impregnation time, the absorptions of both specimens were 0.89 to $10.18 \mathrm{mg} / \mathrm{cm}^{3}$ and 1.26 to $12.07 \mathrm{mg} / \mathrm{cm}^{3}$, respectively. Based on the difference in vinegar temperature, the difference of absorption varied significantly (5\%) by Duncan's multiple range tests, expressed by different alphabets, even for those specimens that had undergone a different pre-process. This suggests that the absorption of bamboo vinegar by the specimens increased with the increase in the duration of the treatment. These results were the same as reported previously (Lin et al., 2006a; Shiah et al., 2006; Lin et al., 2006b).

\section{Effect of vinegar with the different collection tem- perature on fungi resistance}

The results of the steamed specimens treated with vinegars of different collection temperature for $60 \mathrm{~min}$ of vacuum and 240 min of impregnation, and after being inoculated by various fungi on WA at $25^{\circ} \mathrm{C}$, and then incubated for 70 days are shown in Fig. 1.

The fungi resistance of the control specimens, not treated with any bamboo vinegar, was nil (100\% of fungal colony growth) after having been inoculated by various fungi for 10 days (no data is shown in Fig. 1). However, after having been treated with the vinegar of each temperature, the specimens were fungal resistant to various degrees. For the vinegar at a temperature of $80-150{ }^{\circ} \mathrm{C}$, the fungal colony growth (growth rate) of Aspergillu flavus was $82 \%$ after 20 days of inoculated time, the growth rate was about 50-85\% for Aspergillus niger, Penicillum Citrinum and Trichoderma viride, and it was 20\% for Mucor sp., but 0\% for the airborne fungi particles. The growth rate of the specimen treating the vinegar with over 80 and $145-150{ }^{\circ} \mathrm{C}$ was about 33-65\% for Aspergillu flavus, Aspergillus niger, Mucor sp. and Penicillum Citrinum after 70 days of inoculated time, but it was only about 0-20\% for both Trichoderma viride and the airborne fungi particles. For the vinegars at a temperature of 90-92 and 99-102 ${ }^{\circ} \mathrm{C}$, the growth rate of Aspergillu flavus and Mucor sp. was about 30-70\%, but it was about 0 to $35 \%$ for the others. The growth rate of the specimens treated with vinegar of $120-123{ }^{\circ} \mathrm{C}$ was $0 \%$ for all fungi inoculat-
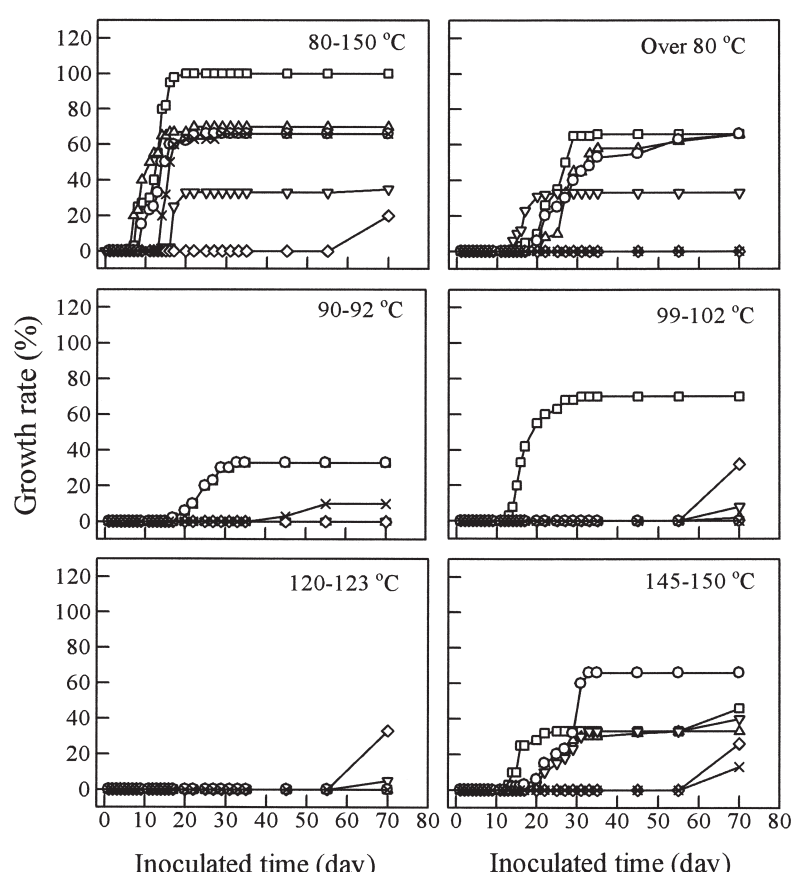

Fig. 1. Fungi resistance of Moso bamboo steaming process specimens with bamboo vinegar from different collection temperatures by $60 \mathrm{~min}$ of vacuum period and $240 \mathrm{~min}$ of impregnation treatments.

Symbols: $-\square-:$ Aspergillus flavus; $-\triangle$ :Aspergillus niger; $\neg-$ :Mucor sp.; $\_$: Airborne fungi particles; -○-: Penicillium Citrinum; $\star \star$ : Trichoderma viride.

ed for 70 days, and the growth rate for airborne fungi particles was about 30\%. The above indicates that bamboo vinegars collected at different temperatures can restrain bamboo molds at different rates and decrease the microbiological deterioration of products made with bamboo. The above also indicates that the fungi resistance of bamboo materials is influenced by the temperature of the bamboo vinegar at which it is extracted. This study suggests that it is critical for future research to investigate which of the organic compounds in Moso bamboo vinegar, and at which temperature are the main fungicides.

A microscope observation for the fungi resistance of the steamed specimens at a temperature of $120-123^{\circ} \mathrm{C}$ is shown in Fig. 2. The 300 times SEM micrograph of the cross section of the steamed specimens, treated for 


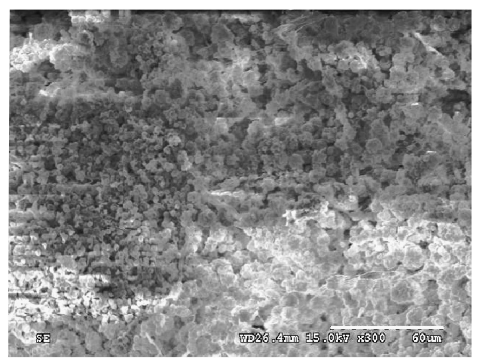

Control

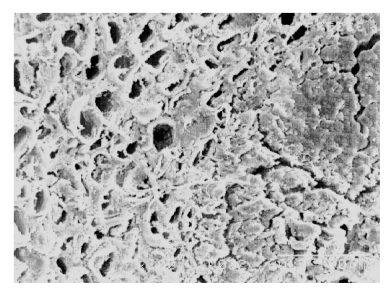

Aspergillus flavus

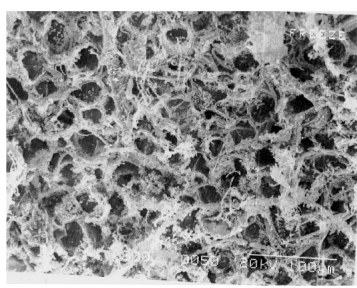

Airborne fungi particles

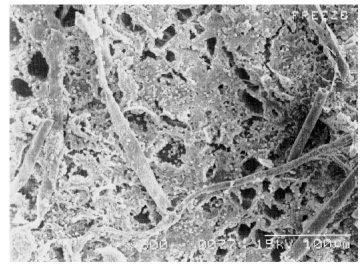

Aspergillus niger

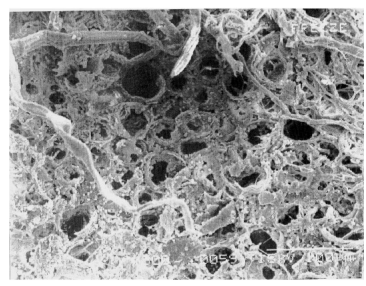

Penicillium citrinum

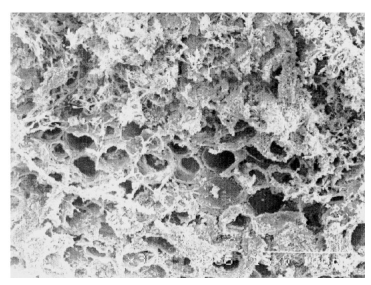

Mucor sp.

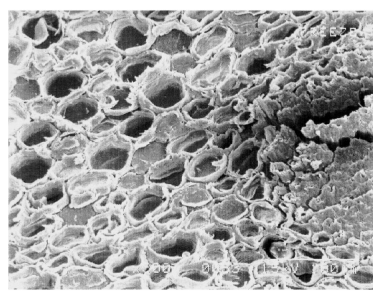

Trichoderma viride

Fig. 2 SEM photographs $(\times 300)$ of for various fungi resistances of Moso bamboo vinegar from the collected temperature at $120-123^{\circ} \mathrm{C}$ for steaming process specimens by $60 \mathrm{~min}$ of vacuum period and 240 min of impregnation treatments after 70 days.

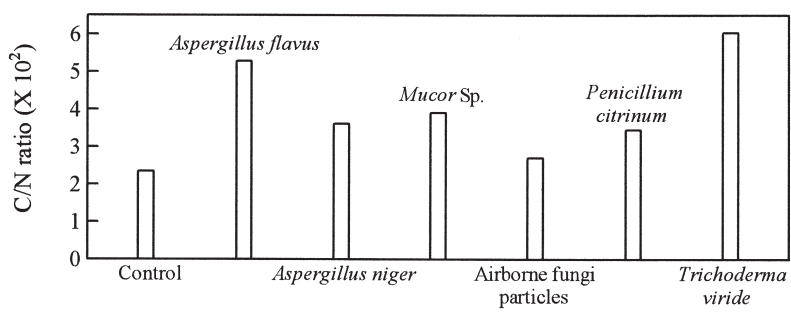

Fig. 3. $\mathrm{C} / \mathrm{N}$ ratio of various fungi inoculated on steaming process specimens with Moso bamboo vinegar from the collected temperature at $120-123^{\circ} \mathrm{C}$ by 60 min of vacuum period and 240 min of impregnation treatments after 70 days.

60 min with vacuum and impregnated for $240 \mathrm{~min}$, after having been inoculated for 70 days with various fungi, indicated that there was no fungal colony growth besides the airborne fungi particles (shown by the middle figure on the left side of Fig. 1) and the control specimen. The results of the $\mathrm{C} / \mathrm{N}$ ratio indicated that the control specimens and the specimens with airborne fungi particles were lower than the specimens after being inoculated by various fungi for over 70 days (Fig. 3). This is because the fungi of amino acid were increased from metabolism of fungal microorganisms (Fujida, 1993; Rayner and
Boddy, 1988; Fukuda, 2000; Lin, 2003), confirming that the lower the $\mathrm{C} / \mathrm{N}$ ratio, the greater the rate of biodegradation.

\section{Effect of treatment on fungi resistance}

A comprehensive examination was carried out, including the visual responses for two types of bamboo materials that were treated with bamboo vinegar by 60 min of vacuum and 240 min of impregnation and subsequently inoculated with 5 sorts of fungi as well as being exposed to airborne fungi particles. One of the results for the investigation of Aspergillu flavus is shown in the top of Fig. 4. The control specimen showed that neither of the pre-processed treatments was ineffective against fungi. (Aspergillus flavus inoculated on WA at $25^{\circ} \mathrm{C}$ incubator for 5 days showed $100 \%$ of fungal colony growth). The growth rate of the specimens treated with vinegar at $80-150{ }^{\circ} \mathrm{C}$ was about $70 \%$ for the steamed specimen and $33 \%$ for the heated one, when using vinegar over $80^{\circ} \mathrm{C}$ the growth rate was $65-70 \%$ for both specimens, and for the vinegar at $145-150{ }^{\circ} \mathrm{C}$ and the growth rate was about 33\% for the steamed specimen and $15 \%$ for the heated one. After treating the specimens with vinegar at 90-92, 99-102 and 120- 
$60 \mathrm{~min}$ of vacuum period and $240 \mathrm{~min}$ of impregnation treatment

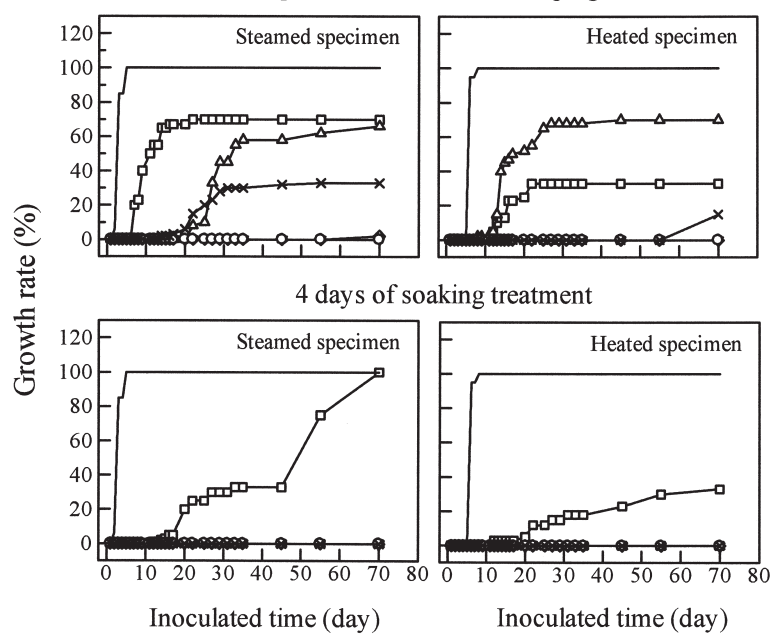

Fig. 4. Aspergillus flavus resistance of Moso bamboo steaming process specimens with bamboo vinegar from different collection temperatures by $60 \mathrm{~min}$ of vacuum period and 240 min of impregnation and 4 days of soaking treatments.

Symbols: ——: Control; $-\square-: 80-150^{\circ} \mathrm{C} ;-\triangle-$ : over $80^{\circ} \mathrm{C}$;

$\nabla-: 90-92^{\circ} \mathrm{C} ; \prec-: 99-102{ }^{\circ} \mathrm{C} ;-\circ-: 120-123^{\circ} \mathrm{C}$; $\star: 145-150{ }^{\circ} \mathrm{C}$. $123^{\circ} \mathrm{C}$, the fungi resistance of both specimens was effective on Aspergillus flavus ( $0 \%$ of growth rate). However, the results through microscopic observations showed that after being Aspergillus flavus inoculated for 70 days the cross section of the specimen treated with vinegar at $90-92$ and $99-102{ }^{\circ} \mathrm{C}$, there were an unacceptably from the SEM (×300) photograph (Fig. 5), indicating the strains of Aspergillus flavus were found. Only the specimen treated with vinegar at $120-123^{\circ} \mathrm{C}$ showed that there were no strains of Aspergillus flavus remaining on the surface of the cross section.

On the other hand, the bottom of Fig. 4 also shows the results for both specimens that received a 4-day soaking treatment for Aspergillus flavus resistance. Both control specimens (steamed and heated specimens without any vinegar) proved to be ineffective for fungi resistance. After 3-5 days, it showed a $100 \%$ of growth rate, but it was enable to obtain a better fungi resistance, after being inoculated with Aspergillus flavus for 70 days, for treating the specimens with vinegar of a temperature over 80, 90-92, 99-102, 120-123 and 145$150{ }^{\circ} \mathrm{C}$, resulted in no the strain of Aspergillus flavus ( $0 \%$ of growth rate), except for the specimen treated with vinegar at $80-150{ }^{\circ} \mathrm{C}$, the growth rate was $100 \%$ for the steamed specimen and about 33\% for the heated

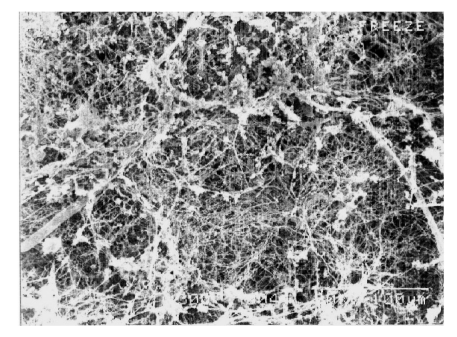

Control

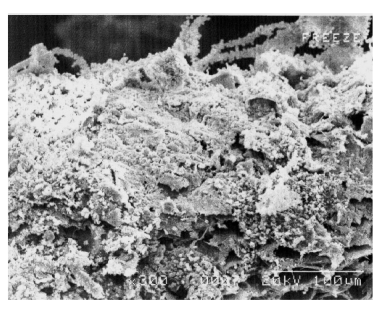

$80-150{ }^{\circ} \mathrm{C}$

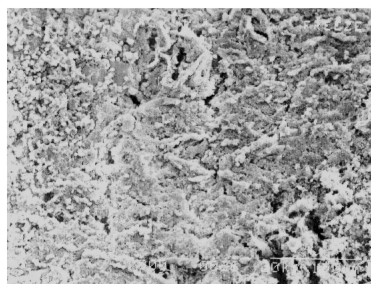

$99-102{ }^{\circ} \mathrm{C}$

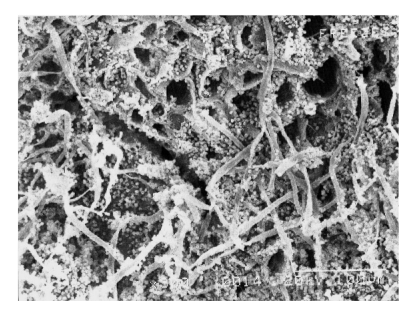

Over $80^{\circ} \mathrm{C}$

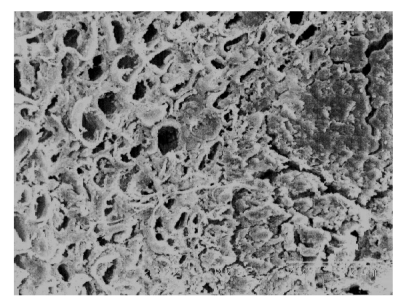

$120-123^{\circ} \mathrm{C}$

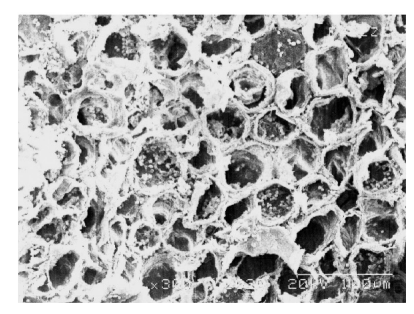

90-92 ${ }^{\circ} \mathrm{C}$

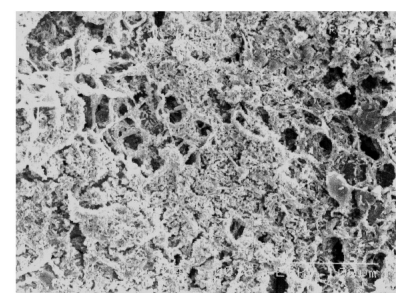

$145^{-150}{ }^{\circ} \mathrm{C}$

Fig. 5 SEM photographs (X 300) of for Aspergillus flavus resistances of Moso bamboo vinegar collected from different temperatures for steaming process specimens by $60 \mathrm{~min}$ of vacuum period and 240 min of impregnation treatments after 70 days. 
one.

When we compare the different treatments of the specimens: whatever the fungus was that was being inoculated, the 4 days of soaking treatment ended up with better results than the one using the treatment consisting of $60 \mathrm{~min}$ of vacuum and $240 \mathrm{~min}$ of impregnation. This is because the fungi resistance of various molds is related to the amount of vinegar absorption (see Table 3 ), regardless of the different collection temperatures. Therefore, it is suggested that the fungi resistance is followed by the increase of the vinegar absorption. These results were the same as in previous reports (Lin et al., 2006a; Shiah et al., 2006; Lin et al., 2006b).

As described above, bamboo vinegar with different collection temperatures can restrain bamboo molds and reduce the microbiological deterioration of bamboo materials. It is believed that the application of bamboo vinegar with a high level of absorption can prevent mildew attack on bamboo surfaces. To obtain a higher fungi resistance of the bamboo materials, further experiments are needed to obtain higher bamboo vinegar concentrations, and a longer soaking times, and/or a higher treating pressure are also recommended.

\section{ACKNOWLEDGEMENTS}

The authors are grateful to the Pu Yuan Co. Ltd., Nantour, Taiwan, for providing the experimental materials, 2 sorts of pre-process Moso bamboo materials, and the divisions of forest utilization, TFRI Taipei, Taiwan for supplying bamboo vinegar. We offer our sincere appreciation to both the National Science Council in Taiwan (NSC 93-2622-E-003-CC3), and the Huei Yuh Industry Co. Ltd., Taipei, Taiwan for financial support.

\section{REFERENCES}

Austin, R., K. Ueda. 1970 Bamboo. John Weatherhill, Inc., New York, pp. 101-156

Fujida, K. 1993 Composite Technology. Gihoutou Publication, pp. $69-70$

Fukuda, K. 2000 Deterioration and Increasing Durability of Thatched Roof. Data of Wood Research, 16: 1-16

Hageta, Y. 2004 Application of Wood/Bamboo Vinegar on the Cultivation of Grape. Nobunkyou Publication, pp. 84-85.

Ikimoto, T., O. Ikeshima. 2000 Usages of Bamboo Charcoal and Bamboo Vinegar. Nobunkyou Publication, pp. 89-107

Kobahasi, Y. 2004 Reductive Effectives of Agricultural Chemical. Nobunkyou Publication, pp. 146-149

Lin, F. C. 1995 Agricultural Usage of Bamboo Charcoal and Bamboo Vinegar. TanYi Publication, pp. 28-30

Lin, J. C. 2003 Investigation and Analysis on Weather Degradation of Wood Construction Materials for Traditional Taiwanese Architectures. Ph. D Dissertation, pp. 144-157

Lin, H. C., T. Ohuchi, Y. Murase, T. C. Shiah, S. L. Shieh, P. C. Chiu, Y. M. Juan and S. C. Cheng 2006 Application of Bamboo Vinegar with Vacuum Process to Evaluate Fungi Resistance of Bamboo Materials. Journal of the Faculty of Agriculture Kyushu University. Japan, 51(1): 5-11

Lin, H. C. and T. C. Shiah 2006 Evaluation of Fungi Resistance of Moso Bamboo Materials Using Bamboo Vinegar with Smoking Process. Quart. Journal Forest Research of Taiwan. Taiwan ROC, 28(2): 51-66

Mizuki, B. 2004 Decrease of Agricultural Chemical to Apple Tree. Nobunkyou Publication, pp. 86-88

Nomura, R. 2004. Healthy Effects of Bamboo Vinegar. Nobunkyou Publication, pp. 141-143

Okano, K., M. Suzuki, M. Haishi, K. Zonomoto, N. Zouta, T. Takahashi, H. Nitakai, I. Minadokuchi, and T. Akiyama. 1995 Wooden Residence Environment - Handbook Asakusa Publication, Japan, pp. 114-122

Rayner, A. D. M., L. Boddy. 1988 Fungal decomposition of Wood-Its Biology and Ecology. A Wiley-Interscience Publication, Chichester, New York, Brisbane, Toronto, Singapore, pp. 38-46

Shiah, T. C., S. K. Wu, J. C. Huang and H. C. Lin 2006 The fungi resistance of bamboo materials treated with bamboo vinegar using soaking treatment. Journal of Agriculture and Forestry, NCYU, 3(1): 1-22

TAPPI 1993 Fungus Resistance of Paper and Paperboard. Microbiology and Microbial Technology Committee of Research and Development Division, pp. 1-4

Uchimura, T., H. Tanikai and K. Hosoukawa 2000 Issues of Bamboo Charcoal and Bamboo Vinegar. Soumorisya Publication, pp. 138-168

Yoshie, L. 2004 Effects of Wood/Bamboo Vinegar on Cow Skin. Nobunkyou Publication, pp. 132-133 